Gertie F. Marx MD, Michael F. Domurat MD, Melania Costin MD

\title{
Potential hazards of hypoglycaemia in the parturient
}

\begin{abstract}
Hypoglycaemia can cause serious problems in anaestherized patients, due so blockade by anaesthesia of the usual compensatory mechanisms. Gravid women develop hypoglycaemia more readily than non-pregnant patients because they live in a state of "accelerased starvation." Three cases are described of healthy parturients undergoing elective Caesarean section under lumbar epidural analgesia whose post-blockade hypotension was difficult to reverse until their low blood glucose concentrations had been normalized. Further investigarions of the role played by blood glucose concentrations in the maintenance of cardiovascular homeostasis in pregnant women are indicated. In the meantime, a preanaesthetic blood glucose determination will facilitate measures to ensure a normal blood glucose level before induction of anaesthesia for Caesarean section.
\end{abstract}

A hypoglycaemic state can cause serious problems in the anaesthetized patient due to blockade by anaesthesia of the usual compensatory mechanisms. In general, hypoglycaemia stimulates the release of epinephrine from the adrenal medulla; this induces the breakdown of glycogen to glucose in liver and muscles and simultaneously leads to increases in systolic pressure and heart rate. The output of epinephrine, however, is decreased during high regional analgesia so that the hyperglycaemic response is blocked and hypotension rather than hypertension may ensue. ${ }^{1,2}$

We are reporting the course of two healthy wellnourished parturients who, following institution of routine lumbar epidural analgesia (LEA) for elective Caesarean section, developed severe hypotension which was difficult to reverse - despite invoking the usual therapeu-

\section{Key words}

ANAESTHESIA: obstetric; METABOLISM: blood glucose, hypoglycaemia, pregnancy.

From the Department of Anesthesiology, Albert Einstein College of Medicine, The Bronx, New York.

Address correspondence to: Dr. Gertie F. Marx, Department of Anesthesiology - I 1226, Albert Einstein College of Medicine, 1300 Morris Park Avenue, Bronx, NY 10461. tic measures - until after their low blood glucose levels had been normalized. In an additional hypoglycaemic woman, maintenance of normotension appeared to be facilitated by IV dextrose administration. Although we usually determine blood glucose concentrations preoperatively in women scheduled for abdominal delivery and do not start the administration of anaesthesia until a level of $4.44-5.55 \mathrm{mmol} \cdot \mathrm{L}^{-1}\left(80-100 \mathrm{mg} \cdot \mathrm{dl}^{-1}\right)$ has been reached, this testing had been omitted in the three patients, who had been fasting since about $1800 \mathrm{H}$ on the previous evening.

Our routine for performance of LEA for Caesarean section is as follows: after IV infusion of at least $1,100 \mathrm{ml}$ of an electrolyte solution, the gravida is placed in the right lateral decubitus position; while the inlusion is maintained at a rate of approximately $1,000 \mathrm{ml} \cdot \mathrm{h}^{-1}$, the epidural space is identified; small aliquots of three per cent 2-chloroprocaine are injected two misutes apart; then a catheter is inserted and the patient turned to the supine position with a wedge placed underneath the right hip; additional local anaesthetic is given as needed and the operating table tilted left-side-down until the patient's umbilicus points toward the wall.

\section{Case reports}

Case I

A bealthy multipara with three previous abdominal deljveries underwent repeat Caesarean section early in the monning. LEA was achieved with $26 \mathrm{ml}$ of three per cent 2-chloroprocaine following prehydration with $1,200 \mathrm{ml}$ of lactated Ringer's solution. Preoperative blood pressure was $120 / 80 \mathrm{mmHg}$ and fasting blood sugar below 3.33 $\mathrm{mmol} \cdot \mathrm{L}^{-1}\left(60 \mathrm{mg} \cdot \mathrm{dl}^{-1}\right)$. Fifteen minutes after reaching a sensory level to $\mathbf{T}_{4}$, the blood pressure declined to $80 / 50 \mathrm{mmHg}$ despite an additional $400 \mathrm{ml}$ of fluid and failed to respond to three $10 \mathrm{mg}$ IV doses of ephedrine. A bolus of $25 \mathrm{~g}(50 \mathrm{ml})$ of dextrose given as an IV push was followed by a rise in blood pressure to $105 / 60 \mathrm{mmHg}$ at which level it stabilized for the remainder of the surgical procedure. Blood glucose determined $10 \mathrm{~min}$ after the dextrose load was $7.2 \mathrm{mmol} \cdot \mathrm{L}^{-1}\left(130 \mathrm{mg} \cdot \mathrm{dl}^{-1}\right)$. The infant, delivered during the period of hypotension, had Apgar scores of six and nine, at one and five minutes respectively. 


\section{Case 2}

A 26-year-old primigravida was schedulcd for an elective Caesarean section because of a prior myomectomy. LEA was commenced following hydration with $1,250 \mathrm{ml}$ of lactated Ringer's solution. Twenty-four $\mathrm{ml}$ of three per cent 2-chloroprocaine were injected resulting in a sensory level of $T_{4}$. Five min after positioning the patient for surgery, blood pressure fell from the preoperative level of $100 / 70 \mathrm{mmHg}$ to $80 / 50 \mathrm{mmHg}$, and the patient began to complain of sweating and nausea. Despite three IV injections of $10 \mathrm{mg}$ of ephedrine, the blood pressure did not respond. Blood glucose was then measured and showed a concentration of $2.22 \mathrm{mmol} \cdot \mathrm{L}^{-1}\left(40 \mathrm{mg} \cdot \mathrm{dl}^{-1}\right)$. A $25 \mathrm{~g}$ bolus of dextrose $(50 \mathrm{ml})$ was administered IV, followed by prompt relief of the patient's symptoms, rapid return of her blood pressure to the preoperative level, and increase of her bload glucose to $6.1 \mathrm{mmol} \cdot \mathrm{L}^{-1}$ $\left(110 \mathrm{mg} \cdot \mathrm{dl}^{-1}\right)$. The infant's Apgar scores were six and nine.

\section{Case 3}

A healthy 28-yeat-old term-pregnant woman was scheduled for repeat classical Caesarean section at $0800 \mathrm{H}$. Following hydration with $1,100 \mathrm{ml}$ of lactated Ringer's solution, lumbar epidural analgesia was instituted using $20 \mathrm{ml}$ of three per cent 2-chloroprocaine. Ten minutes after establishing a $\mathrm{T}_{6}$ sensory level, systemic blood pressure fell from the preoperative value to $120 / 80 \mathrm{mmHg}$ to $80 / 60 \mathrm{mmHg}$ despite continued IV hydration and appropriate left uterine displacement (as described). The rate of IV infusion was increased, further ephedrine $10 \mathrm{mg}$ was administered IV, and blood pressure rose to $105 / 70$ $\mathrm{mmHg}$. The baby was delivered in good condition (Apgar scores nine and ten). A second episade of hypotension to $85 / 50 \mathrm{mmHg}$ followed $10 \mathrm{~min}$ later despite minimal blood loss and required two additional $10 \mathrm{mg}$ boluses of ephedrine to raise the systolic pressure above $100 \mathrm{~mm} \mathrm{Hg}$. At this time, a Dextrostix blood glucose determination revealed a level below $\left.3.33 \mathrm{mmol}-\mathrm{L}^{-1}(60 \mathrm{mg} \cdot \mathrm{d})^{-1}\right)$. The IV infusion was immediately changed to a five per cent dextrose-containing solution at a rate of $1,200 \mathrm{ml} \cdot \mathrm{h}^{-1}$, preceded by a $400 \mathrm{ml}$ bolus, and blood pressure remained stable thereafter. Repeat blood glucose was not obtained.

\section{Discussion}

The actual blood glucose concentration below which energy requirements can no longer be met varies on an individual basis. In normal nonpregnant subjects, signs of hypoglycaemia usually begin when the level decreases to about $2.78 \mathrm{mmol} \cdot \mathrm{L}^{-1}\left(50 \mathrm{mg} \cdot \mathrm{dl}^{-1}\right) .{ }^{3}$ In pregnant women, however, hypoglycaemia is defined as a blood glucose level below $3.33 \mathrm{mmol} \cdot \mathrm{L}^{-1}\left(60 \mathrm{mg} \cdot \mathrm{dl}^{-1}\right){ }^{4}$ In addition, gravid women develop low blood glucose concentrations more readily than surgical patients because they live in a state of "accelerated starvation" characterized by a tendency toward fasting hypoglycaemia. First, the fuel demands of the developing fetus are met primarily by the consumption of glucose and, second, secretion of insulin in response to glucose is augmented. As early as 15 weeks of gestation, maternal glucose levels after an overnight fast are $0.83-1.11 \mathrm{mmol} \cdot \mathrm{L}^{-1}\left(15-20 \mathrm{mg} \cdot \mathrm{dl}^{-1}\right)$ lower than in the nongravid state and, as fasting extends beyond 12 hours, blood glucose declines to $2.22-2.50 \mathrm{mmol} \cdot \mathrm{L}^{-1}$ $\left(40-45 \mathrm{mg} \cdot \mathrm{dl}^{-1}\right) .^{5}$ An analysis of hypoglycaemic episodes occurring in 94 adult patients hospitalized at a tertiary care hospital revealed that nine cases were associated with pregnancy. Of these, six had no risk factors other than limited caloric intake during labour and delivery while two women suffered from diabetes and one from eclampsia and shock. ${ }^{6}$

We measured fasting blood glucose levels in 110 non-diabetic gravidae scheduled for elective Caesarean section at $0800 \mathrm{H}$ in our hospital where dinner is served at $1730 \mathrm{H}$. The first 60 women were evaluated in 1980 at which time a snack was provided at $2030 \mathrm{H}$ on the evening before surgery; glucose levels ranged between $2.22-5.00$ $\mathrm{mmol} \cdot \mathrm{L}^{-1}\left(40-90 \mathrm{mg} \cdot \mathrm{dl}^{-1}\right)$ and were below $3.33 \mathrm{mmol}$. $\mathrm{L}^{-1}\left(60 \mathrm{mg} \cdot \mathrm{dl}^{-1}\right)$ in 29 patients ( 48 per cent). ${ }^{6}$ In a second group of 50 women assessed in 1984 when the evening snack was no longer offered, fasting blood glucose levels measured below $3.33 \mathrm{mmol} \cdot \mathrm{L}^{-1}\left(60 \mathrm{mg} \cdot \mathrm{dl}^{-1}\right)$ in $32 \mathrm{pa}$ tients ( 64 per cent) and were $\leq 2.22 \mathrm{mmol} \cdot \mathrm{L}^{-1}$ ( $40 \mathrm{mg}$. $\mathrm{dl}^{-1}$ ) in 15 ( 30 per cent); thus, only three of these gravidae were not hypoglycaemic on arrival in the obstetric operating room (unpublished data). Neither regional nor general anaesthesia was started until after a predetermined amount of glucose had been infused IV.

In a study of serial blood glucose determinations made in 30 women undergoing elective Caesarean section after an ovemight fast, initial levels of $3.0-4.9 \mathrm{mmol} \cdot \mathrm{L}^{-1}$ $\left(55-88 \mathrm{mg} \cdot \mathrm{dl}^{-1}\right)$ were measured which decreased to 2.9-4.7 mmol $\cdot \mathrm{L}^{-1}\left(52-81 \mathrm{mg} \cdot \mathrm{dl}^{-1}\right)$ pre-delivery following an IV "preload" of $2 \mathrm{~L}$ of Hartmann's solution, although a change in mean value from $3.7 \pm 0.08$ to $3.9 \pm 0.07 \mathrm{mmol} \cdot \mathrm{L}^{-1}$ indicates that some of the parturients were able to raise their blood glucose slightly. ${ }^{8}$ In contrast, in 24 normal non-fasting, late-pregnant women, mean diurnal plasma glucose was $4.69 \pm 0.37 \mathrm{mmol} \cdot \mathrm{L}^{-1}$ $\left(85 \pm 5 \mathrm{mg} \cdot \mathrm{dl}^{-1}\right.$ ) and on a diurnal profile, the glucose level did not decline below $4 \mathrm{mmol} \cdot \mathrm{L}^{-1}\left(72 \mathrm{mg} \cdot \mathrm{dl}^{-1}\right){ }^{9}$

Glucose is transported by "facilitated diffusion" from mother to fetus whereas maternal insulin fails to traverse the placenta. Consequently, maternal hyperglycaemia leads to exaggerated fetal glucose levels which, in turn, stimulate fetal insulin secretion. ${ }^{5}$ Following birth, de- 
prived of the influx of maternal glucose, the neonate may develop "reactive" hypoglycaemia during the first two hours of life, provided the maternal concentration was $6.7 \mathrm{mmol} \cdot \mathrm{L}^{-1}\left(120 \mathrm{mg} \cdot \mathrm{dl}^{-1}\right)$ or higher. ${ }^{10} \mathrm{In}$ order to avoid this complication, a trend has developed to infuse dextrose-free electrolyte solutions as a "preload" before Caesarean section. ${ }^{8}$ The potential risks of maternal hypoglycaemia, however, may be too serious to warrant this practice without first confirming a normal blood glucose level. Bedside measurements of blood glucose are easy to perform. Test strips provide reliable information within 1-2 min and can be performed on capillary, venous, arterial or mixed blood. An additional consideration is that of the recently noted relationship between maternal blood glucose concentration and the incidence of fetal brcathing movements: human and lamb studies have shown that matemal fasting reduces the incidence of fetal breathing movements. ${ }^{11,12}$ Thus, maternal normoglycaemia may be beneficial for the initiation of respiratory activity in the infant at birth.

Further investigations of the role played by blood glucose concentrations in the maintenance of cardiovascular homeostasis in pregnant women are indicated. In the meantime, a preanaesthetic blood glucose determination will facilitate measures to ensure normoglycaemia before induction of anaesthesia for Caesarean section - for maternal and fetal reasons. Kenepp et al. ${ }^{13}$ have recommended the IV administration of $6 \mathrm{~g} \cdot \mathrm{hr}^{-1}$ of dextrose before Caesarean section. We believe that individualization is more rational. We have found that gravidae with a fasting blood glucose concentration of abour $2.22 \mathrm{mmol}$. $\mathrm{L}^{-1}$ ( $40 \mathrm{mg} \cdot \mathrm{dl}^{-1}$ ) requife $15-25 \mathrm{~g}$ of dextrose to raise the level to approximately $5.55 \mathrm{mmol} \cdot \mathrm{L}^{-1}\left(100 \mathrm{mg} \cdot \mathrm{dl}^{-1}\right)$, whereas women with a fasting concentration of about $3.33 \mathrm{mmol} \cdot \mathrm{L}^{-1}\left(60 \mathrm{mg} \cdot \mathrm{dl}^{-1}\right)$ need only $12-15 \mathrm{~g}$ of dextrose.

\section{References}

I Engquist A, Brandt MR, Fernandez A et al. The blacking effect of epidural analgesia on the adrenocortical and hyperglycaemic responses to surgery. Acta Anaesthesiol Scand 1977; $21: 330-5$.

2 Jenkins $M T$, Beck $C P$. Differential diagnosis of hypotension occurring during anesthesia and surgery. Chapter 7, pp 104-15. In: Jenkins MT (Ed). Anesthesia for Patients with Endocrine Disease. Philade]phia, F. A. Davies, 1963.

3 Moorthy SS. Metabolism and Nutrilion. Chapler 24, pp 485-521. In: Stoelting RK, Dierdor SF (Eds). Anesthesia and Co-Existing Disease. New York, Edinburgh, London, Melbourne, Churchill Livingstone, 1983.

4 Bergman $M$, Seaton $T B$, Auerhahn $C C$ et al. The incidence of gestational hypoglycemia in insulin-dependent and non-insulin-dependent women. NY State J Med 1985; 86: 174-7.

5 Felig $P$. Diabetes Mellitus. Chapter 5, pp 170-95. In Burow GN, Ferris TP (Eds). Medical Complications During Pregnancy. Philadelphia, London, Toronto, W. B. Saunders, 1975.

6 Fischer $K F$, Lees $J A$, Newman $J H$. Hypoglycemia in hospitulized patients. Causes and outcome. N Engl J Med 1986; 315: 1245-50

7 Jawalekar S, Marx GF. Effect of I.V. fluids on maternal and fetal blood glucose. Anesthesiology 1980; 53 : S311.

8 Thomas $P$, Buckley $P$, Fox $M$. Matemal and neonatal blood glucose after crystalloid loading for epidural Caesarean section. Anaesthesia 1984; 39: 1240-2.

9 Gillmer MGD, Beard RW, Brooke FM, Oakdey NW. Carbohydrate metabolism in pregnancy. Part I. Diurnal plasma glucose profile in normal and diabetic women. Br Med J 1975; 3: 399-404.

10 Mendiola $J$, Grylack $L J_{r}$ Scanlon $J W$. Effects of intrapartum matemal glucose infusion on the nomal fetus and newborn. Anesth Analg 1982; 61: 32-5.

11 Bocking A, Adamson L, Cousin A et al. Effects of glucose injections on human fetal breathing movements and gross fetal body movements at 38 to 40 weeks' gestational age. Am J Obstet Gynecol 1982; 142: 606-11

12 Richardson $B$, Hohimer AR, Mueggler P. Bissonnette J. Effects of glucose concentration on fetal breathing movements and electrocortical activity in fetal lambs. Am J Obstet Gynecol 1982; 142: 678-83.

13 Kenepp NB, Shelley WC, Gabbe SG. Kumar S, Stanley CA, Gutsche BB. Fetal and neonatal hazards of maternal hydration with $5 \%$ dextrose before Caesarean section. Lancet 1982; 1: 1150-2.

\section{Résumé}

L'hypoglycémie peut causer de sérieux problèmes chez les patients anesthésiés, en raison du blocage des mécanismes rompensatoires hahituels. Les femmes enceintes développent une hypoglycémie plus facilement que les patientes qui ne sont pas enceintes parce qu' elles vivent dans un état de "d' inanition accélérée". On décrit trois parturientes en santé, subissant une césarienne élective sous antesthésie péridurale tombaire, pour lesquelles on a éprouvé de la difficulté à inverser l'hypotensiont post bloc avani que leur glycémie ne soit normalisée. On signale la poursuite des recherches sur le rôle que joue la glycémie dons le maintien de l'homéostase cardiovasculaire chez la fermme enceinte. Entre-ternps, la détermination préanesthésique de la glycémie facilitera les mesures à prendre afin d'assurer une glycémie normale avant l'induction de l'anesthésie pour une césarienne. 